\title{
Modulatory effect of baicalein on gene expression and activity of antioxidant enzymes in streptozotocin-nicotinamide induced diabetic rats
}

\author{
Purabi Sarkar', Kaberi Nath', Sofia Banu*,1 \\ ${ }^{1}$ Department of Bioengineering and Technology, Gauhati University, Guwahati, Assam, India
}

\begin{abstract}
Oxidative stress plays the central role in the pathogenesis and progression of diabetic complications. The present study aims to investigate the beneficial effect of oral administration of flavone baicalein in streptozotocin-nicotinamide (STZ-NA) induced diabetic rats by measuring oxidative stress markers, antioxidant enzyme activities and expression analysis of antioxidant genes. Experimental diabetes was induced by a single intraperitoneal (i.p.) injection of STZ (55 mg $/ \mathrm{kg}$ b.wt), $15 \mathrm{~min}$ after the i.p. administration of NA. At the end of the experimental period, thiobarbituric acid reactive substances (TBARS), activities of antioxidant enzymes and expression levels of superoxide dismutase (SOD), catalase (CAT), glutathione (GSH) and glutathione peroxidase (GPx) were measured in diabetic rats along with serum biochemical parameters namely total cholesterol (TC), total triglyceride (TG), aspartate transaminase (AST) alanine transaminase (ALT) and glycosylated hemoglobin (HbA1c). Oral administration of baicalein $(40 \mathrm{mg} / \mathrm{kg}$ b.wt/day) demonstrated a significant ameliorative effect on all studied biochemical and oxidative stress parameters. Biochemical findings were corroborated by qPCR expression analysis which showed significant upregulation of antioxidant genes in diabetic rats. These results suggest that baicalein supplementation may reduce diabetes and its complications by suppressing oxidative stress and enhancing gene expression and antioxidant enzyme activities in diabetic rats.
\end{abstract}

Keywords: Diabetes. Streptozotocin/pharmacology. Baicalein/pharmacology. Nicotinamide/ pharmacology. Glibenclamide. Diabetes Mellitus/Experimental/prevention and control. Gene Expression/ drug effects. Antioxidants/pharmacology. Glyburide/pharmacology. Rats.

\section{INTRODUCTION}

Diabetes mellitus (DM) is a metabolic disorder characterized by elevated levels of glucose in the blood (hyperglycemia) and insufficiency of production or action of insulin produced by the pancreas in our body (Maritim, Sanders, 2003). Diabetes is currently affecting more than 100 million people worldwide. Oxidative stress plays a pivotal role in the onset and progression of diabetic complications (Ayepola, Brooks, Oguntibeju, 2014). Oxidative stress results from an imbalance between the production and neutralization of reactive oxygen species (ROS) such as highly reactive hydroxyl radicals, superoxide anion, peroxyl radicals, singlet oxygen, peroxynitrite, and hydrogen peroxide (Sellamuthu et

\footnotetext{
*Correspondence: S. Banu. Department of Bioengineering and Technology, GUIST, Gauhati University, Guwahati-781014, Assam, India. Mobile: +91- 8638580320. Fax:+91- 3612700311. E-mail: sofiabanu2@gmail.com
}

al., 2013). Oxidative stress-induced complications from diabetes include neuropathy, coronary artery disease, nephropathy, retinopathy (Phillips et al., 2004). There are several reports on altered antioxidant defenses and the role of free radicals in the etiology of diabetes and its complications (Raza et al., 2011). While the external supply of insulin and other medications can control many aspects of diabetes, numerous complications that affect the kidney, peripheral nerves, vascular system, retina, lens, and skin are common and are extremely important factors in terms of longevity and quality of life (Maritim, Sanders, 2003). Increased oxidative stress is a key participant in the development and progression of diabetes and different diabetes-related complications (Giacco, Brownlee, 2010). It is very important to explore the relationship between free radicals, diabetes, and its complications, and to reveal the mechanisms by which increased oxidative stress accelerates the development of diabetic complications, in an effort to find effective treatment options. 
Neutralization of oxidants by increased antioxidant availability may mitigate the effects associated with oxidative stress in DM. The antioxidant systems that fight free radical-mediated damage involves enzymes such as superoxide dismutase (SOD), catalase (CAT), glutathione (GSH), glutathione peroxidase (GPx) as well as non-enzymatic substances such as vitamins A, $\mathrm{C}$ and $\mathrm{E}$, glutathione, $\alpha$-lipoic acid, carotenoids, trace elements like copper, zinc and selenium, as well as coenzyme Q10 (Dehghan, Gargari, Asgharijafarabadi, 2013). As a traditional medicine, plants represent a valuable alternative to control and treat diabetes mellitus with minimal or no side effects in clinical settings, plants also entail relatively lower costs than oral synthetic hypoglycemic agents (Gupta et al., 2005). According to ethnobotanical reports, approximately 800 plants exhibit antidiabetic properties (Patel et al., 2012), and many plants have been recommended for treatment of diabetes (Yajnik, 2001). The principal chemical compounds isolated and identified from these plants are glycans, proteins, and mucilages. Other compounds, such as phenolics, flavonoids, steroids, triterpenoids, and alkaloids, with hypoglycemic activity, have been extracted from these traditionally used medicinal plants by using different organic solvents (Gupta et al., 2006).

One such flavonoid found in the plant Scutellaria baicalensis Georgi is baicalein which shows antioxidant (Gao et al., 1999), anti-inflammatory (Chi et al., 2003), and anti-cardiovascular effects (Wang, Mehendale, Yuan, 2007). S. baicalensis is a medicinal plant which is cultivated in Siberia, Mongolia, the Russian Far East, China, and Korea. The root of S. baicalensis, also known as Huangqin in Chinese, has been used as an ingredient in traditional Chinese medicine formulations for thousands of years. There are more than 40 flavonoids identified from Huangqin that are primarily conjugated with a glucose molecule to form glycosides. Baicalein, baicalin, wogonin, and wogonoside are the main bioactive components found in Huangqin (Li-Weber, 2009). Studies on whether baicalein has an anti-diabetic effect are scarce. But the evidence suggests that baicalein have effects on diabetesrelated complications. Previous studies of Fu et al. (2014) indicated that baicalein reduces blood glucose levels, improves circulating insulin concentration and preserves islet $\beta$-cell mass in obese diabetes mice, suggesting that this compound may have an anti-diabetic effect as loss of $\beta$-cell mass and function is central to the development of diabetes.

Streptozotocin-nicotinamide (STZ-NA) has been extensively used to induce diabetes in experimental animals (Aboonabi, Rahmat, Othman, 2014). STZ causes pancreatic B-cell damage, while NA is administered to partially protect insulin-secreting cells against STZ (Szkudelski, 2012). The cytotoxic action of STZ is associated with the production of ROS which causes oxidative stress and oxidative damage in the cells (Lenzen, 2008). Lipid peroxidation is the main marker for oxidative stress determination. Increased oxidative stress denoted by indices of increased lipid peroxidation, depletion of endogenous antioxidant enzyme activities in plasma etc. is commonly observed in the STZ-NA induced diabetic rats (Nizamutdinova et al., 2009).

Glibenclamide (GC) is a Sulfonylurea anti-diabetic drug used in the treatment of diabetes mellitus. Several antioxidant studies suggest that GC (Elmali, Altan, Bukan, 2004) has the potential to counteract the ROS-mediated oxidative stress.

The present study was undertaken to evaluate the potential effect of baicalein to protect the antioxidant status and ameliorate oxidative stress in STZ-NA diabetic rats. Additionally, the effects of baicalein on the expression levels of antioxidant genes in liver tissues of STZ-NA induced diabetic rats using qPCR system were studied and compared to glibenclamide, a hypoglycemic drug used for type 2 diabetes treatment. As diabetes is a growing public health problem, it is very important to search for novel, low side effects and affordable compounds which can attenuate induced oxidative stress and provide effective treatment for this disease. The present work aims towards this goal.

\section{MATERIALS AND METHODS}

\section{Animals}

Thirty adult male albino Wistar rats weight (180 - $200 \mathrm{~g}$ ) were purchased from College of Veterinary Sciences, Khanapara, Assam, India. The animals were housed in standard polypropylene cages with $12 \mathrm{~h}$ dark/ light cycles and were maintained at $25 \pm 2{ }^{\circ} \mathrm{C}$. Animals were allowed to acclimatize for one week, prior to the experimental procedure. An ethical clarence approval for animal use and the experimental protocol was obtained from Gauhati University Institutional Ethical committee (Animal ethics approval number: IAEC/ PER/2016/2017-2 dated 30/01/2017). The rats were fed a commercial standard pellet diet (Lab 030525, Hindustan Animal Feeds, Gujrat, India), with the chemical composition of protein $24.6 \%$, fat (Ether extract) $4.8 \%$, fat (Acid hydrolysis) $5.5 \%$, crude fiber $4.1 \%$, nitrogenfree extract $50.1 \%$. 


\section{Chemicals and drugs}

Baicalein, Glibenclamide, Nicotinamide, and Streptozotocin were purchased from Sigma-Aldrich Chemicals (St. Louis, MO, USA) and were stored at $2-4{ }^{\circ} \mathrm{C}$ for further use. All the other chemicals were of analytical grade and were purchased from standard commercial suppliers.

\section{Experimental design}

All the experimental rats were divided into six groups, each comprising of five rats designated as follows: Group 1 (NC): Normal control rats receiving $0.1 \mathrm{M}$ citrate buffer ( $\mathrm{pH} 4.5)$.

Group $2(\mathrm{NC}+\mathrm{BC})$ : Normal control rats treated with baicalein $(40 \mathrm{mg} / \mathrm{kg} \mathrm{b}$.wt/day) for 30 days.

Group $3(\mathrm{NC}+\mathrm{GC})$ : Normal control rats treated with glibenclamide $(0.6 \mathrm{mg} / \mathrm{kg}$ b.wt/day) for 30 days.

Group 4 (DC): Diabetic control treated with STZ+NA (55 and $120 \mathrm{mg} / \mathrm{kg}$ b.wt/day respectively).

Group 5 (DC+BC): Diabetic rats treated with baicalein (40 $\mathrm{mg} / \mathrm{kg} \mathrm{b.wt} /$ day) for 30 days.

Group 6(DC+GC): Diabetic rats treated with glibenclamide $(0.6 \mathrm{mg} / \mathrm{kg}$ b.wt $/$ day $)$ for 30 days.

At the end of the total experimental period, the animals were fasted overnight, recorded the final body weight and sacrificed, by cervical dislocation. The serum samples of each rat were obtained by centrifuging blood samples at $4000 \mathrm{xg}$ at $25^{\circ} \mathrm{C}$ for $4 \mathrm{~min}$ and stored at $-20^{\circ} \mathrm{C}$ for further biochemical parameters analysis.

\section{Induction of diabetes}

Overnight fasted rats were injected with a single intraperitoneal (i.p.) injection of freshly prepared STZ $(55 \mathrm{mg} / \mathrm{kg}$ b.wt.) in $0.1 \mathrm{M}$ cold citrate buffer (pH 4.5), and control rats were injected with citrate buffer alone. Nicotinamide was dissolved in normal saline and administered (120 mg/kg b.wt.) $15 \mathrm{~min}$ before STZ administration (Masiello et al., 1998). The rats were allowed to drink $5 \%$ glucose solution overnight to overcome the drug-induced hypoglycemia. The development of diabetes was confirmed by the elevated glucose levels in the blood, which was determined at $72 \mathrm{~h}$ by means of a glucometer (Roche Diabetes Care India Pvt. Ltd. Mumbai, India). The rats with fasting blood glucose level higher than $180 \mathrm{mg} / \mathrm{dl}$ were considered to be diabetic and used in the experiment. The treatment was started on the $4^{\text {th }}$ day after STZ injection, considering that as the $1^{\text {st }}$ day of treatment, which was continued for 30 days.

\section{Preparation of baicalein}

Baicalein (40 mg/kg b.wt/day) was dissolved in dimethyl sulfoxide (DMSO) before it was administered.

\section{Preparation of glibenclamide}

Glibenclamide ( $0.6 \mathrm{mg} / \mathrm{kg}$ b.wt/day) was dissolved in dimethyl sulfoxide (DMSO) before it was administered.

\section{Preparation of tissue homogenate for biochemical parameters}

For tissue preparation, the animals were fasted overnight, anesthetized and sacrificed by cervical dislocation. The liver tissues from all the rats were excised and rinsed with ice-cold saline. The preparation of tissue homogenates was done homogenizing a known amount of the liver in $0.1 \mathrm{M}$ Tris-HCl buffer, $\mathrm{pH} 7.4$ at $4{ }^{\circ} \mathrm{C}$, employing a mortar and a pestle. The homogenates were centrifuged at $3000 \mathrm{x}$ g for $10 \mathrm{~min}$ at $4{ }^{\circ} \mathrm{C}$ using a centrifuge. The supernatant was collected as tissue homogenate, and the same was used for the assay of oxidative stress markers.

\section{Biochemical analysis}

The biochemical parameters for total cholesterol (TC), total triglyceride (TG), aspartate transaminase (AST) and alanine transaminase (ALT) was done by using commercial kits (Span Diagnostics Ltd., India).

\section{Estimation of thiobarbituric acids content}

Tissue homogenates were used for the oxidative stress marker estimations. The thiobarbituric acids content was assayed by measuring thiobarbituric acid reacting substances (TBARS) according to Ohkawa, Ohishi, Yagi (1979). Briefly, to $0.2 \mathrm{~mL}$ of tissue homogenate, $0.2 \mathrm{~mL}$ of SDS (8.1\%), $1.5 \mathrm{~mL}$ of acetic acid $(20 \%, \mathrm{pH}$ above 3$)$, and $1.5 \mathrm{~mL}$ of TBA $(0.8 \%$ aq sol) were added. The mixture was taken to a final volume of $4 \mathrm{~mL}$ with water and then heated in a water bath at $95^{\circ} \mathrm{C}$ for $60 \mathrm{~min}$. After cooling with tap water, 1 $\mathrm{m} \mathrm{L}$ of water and $5 \mathrm{~mL}$ of $\mathrm{n}$ butanol/pyridine $(15: 1 \mathrm{v} / \mathrm{v})$ mixture were added and shaken vigorously. After that it was centrifuged at $4000 \mathrm{xg}$ for $10 \mathrm{~min}$; then, the organic layer was taken and measured at $532 \mathrm{~nm}$ absorbance. The $1,1^{\prime}, 3,3^{\prime}$-tetramethoxypropane was used as a standard. The level of lipid peroxides was expressed as moles of TBARS / $100 \mathrm{~g}$ of tissue. 


\section{Determination of superoxide dismutase (SOD) activity}

Superoxide dismutase was assayed following the method of Misra, Fridovich (1972). The tissue homogenate $(0.1 \mathrm{~mL})$ was mixed by reaction mixtures that contained sodium carbonate $(1 \mathrm{~mL}, 50 \mathrm{mM})$, nitroblue tetrazolium $(0.4 \mathrm{~mL}, 25 \mu \mathrm{m})$, and hydroxylamine hydrochloride $(0.2 \mathrm{~mL}, 0.1 \mathrm{mM})$. The absorbance of the samples was measured at $560 \mathrm{~nm}$.

\section{Determination of catalase (CAT) activity}

The activity of catalase was assayed according to the method of Takahara et al. (1960). Phosphate buffer (1.2 $\mathrm{mL}$ ) and $0.2 \mathrm{~mL}$ of tissue homogenate were mixed, and the reaction was started by the addition of $1.0 \mathrm{~mL}$ of $\mathrm{H}_{2} \mathrm{O}_{2}$ solution. The decrease in the absorbance is measured at $240 \mathrm{~nm}$ at $30 \mathrm{~s}$ intervals for $3 \mathrm{~min}$.

\section{Determination of reduced glutathione (GSH) activity}

Reduced glutathione was determined by the method of Sedlak, Lindsay (1968). $0.5 \mathrm{~mL}$ of tissue homogenate was mixed with $1.5 \mathrm{~mL}$ of $0.2 \mathrm{M}$ Tris buffer with $\mathrm{pH} 8.2$ and then contents were mixed with $0.1 \mathrm{~mL}$ of $0.01 \mathrm{M}$ Ellman's reagent, (5,5'dithiobis-2-nitro-benzoic acid or DTNB), then centrifuged at $3000 \mathrm{x}$ g for $15 \mathrm{~min}$ at RT. The absorbance was read at $412 \mathrm{~nm}$. The GSH content was calculated as mole GSH conjugate formed/gram tissue using molar extinction coefficient of $13.6 \times 10^{3} \mathrm{M}^{-1} \mathrm{~cm}^{-1}$.

\section{Determination of glutathione peroxidase (GPx) activity}

The activity of glutathione peroxidase was assayed by the method of Rotruck et al. (1973). The reaction mixture containing $0.2 \mathrm{~mL}$ of EDTA, $0.1 \mathrm{~mL}$ of sodium azide, $0.1 \mathrm{~mL}$ of $\mathrm{H}_{2} \mathrm{O}_{2}, 0.2 \mathrm{~mL}$ of reduced glutathione, $0.4 \mathrm{~mL}$ of phosphate buffer and $0.2 \mathrm{~mL}$ tissue homogenate was incubated at 37 ${ }^{\circ} \mathrm{C}$ for $10 \mathrm{~min}$. The reaction was arrested by the addition of $3 \mathrm{~mL}$ of disodium hydrogen phosphate and $1.0 \mathrm{~mL}$ DTNB was added to the supernatant, and the colour developed was read at $420 \mathrm{~nm}$ immediately. The enzyme activity was calculated using the molar extinction coefficient.

\section{Extraction of RNA and cDNA Conversion from liver tissue for qPCR analysis}

To study the expression pattern of oxidative stress genes, approximately $300 \mathrm{mg}$ of each rat liver tissue was cleaned with saline. Total RNA was isolated using TRIzol reagent according to the manufacturer's protocol (Life Technologies, Carlsbad, USA). RNA purity and concentration were measured by the NanoDrop quantifier (ThermoFisher Scientific, Waltham, Massachusetts, USA). For cDNA conversion, two micrograms of total RNA was reversed transcribed in a total reaction volume of $20 \mu \mathrm{L}$ by using Superscript III Reverse Transcriptase (Invitrogen, Life Technology, Carlsbad, USA) enzyme following manufacturer's protocols. cDNA produced was further amplified by the qPCR system using the designed set of primers listed in Table I. qPCR was performed with Rotor-Gene Q (Qiagen, Hilden, Germany) PCR System using SYBR PremixEx Taq II master mix according to the protocols provided by the manufacturer (TAKARA BIO INC. Shiga, Japan). Briefly, PCR was performed in a final volume of $20 \mu \mathrm{L}$ including $2 \mu \mathrm{l}$ of $100 \mathrm{ng}$ sample cDNA, $0.2 \mu \mathrm{L}$ of $100 \mathrm{nM}$ forward and reverse primers, and 10 $\mu \mathrm{L}$ Power SYBR green PCR Master Mix. The following thermal cycling profile was used ( 40 cycles): $94{ }^{\circ} \mathrm{C}$ for $20 \mathrm{~s}$, and $56^{\circ} \mathrm{C}$ for $20 \mathrm{~s}, 72{ }^{\circ} \mathrm{C}$ for $20 \mathrm{~s}$. Standard curves for each gene were generated by 1:5 dilutions of cDNA to determine the PCR efficiency of target and reference gene. Standard curves were established by plotting the threshold cycle Ct vs. Log 10 (cDNA). The slope (S) obtained from the standard curve was used to calculate PCR efficiency by the following equation: PCR efficiency $(E)=\left(10^{-1 / \text { slope }}-1\right) \times 100$. Using the $\mathrm{Ct}$ comparative method, the relative abundance of the target transcript was calculated from triplicate samples after normalization

TABLE I - Primers used in qPCR

\begin{tabular}{lll}
\hline Gene & \multicolumn{2}{l}{ Primer (5'-3') } \\
\hline SOD & Forward & GTCCACGAGAAACAAGATGA \\
& Reverse & ATCCCAATCACACCACAAG \\
CAT & Forward & GAATGAGGAGGAGAGGAAAC \\
& Reverse & GGTGGACGTCAGTGAAAT \\
GSH & Forward & CCCAATGGAGTAACAAGTAGG \\
& Reverse & GAGCAGGAAGGAGAGAGAA \\
GPX & Forward & GGGACTACACCGAAATGAA \\
& Reverse & CCTGATGTCCGAACTGATT \\
GAPDH & Forward & TGCACCACCAACTGCTTAGC \\
& Reverse & GGATGCAGGGATGATGTTCT \\
\hline
\end{tabular}


against a housekeeping gene. The housekeeping gene $G A P D H$ was chosen in this study specifically as the most stably expressed reference gene for normalization to ensure reliable results and highest accuracy of the analysis. The mRNA levels (arbitrary units) are expressed in relation to those of the control rats. Relative quantification was calculated using the $2^{-\Delta \Delta C t}$ method, where $\Delta \Delta \mathrm{Ct}=(\mathrm{Ct}$, target $-\mathrm{Ct}, G A P D H)$ treated sample $(\mathrm{Ct}$, target $-\mathrm{Ct}, G A P D H)$ control sample. qPCR results are presented as the mean and SD of the relative fold changes to $2^{-\Delta \Delta \mathrm{Ct}}$ (Livak, Schmittgen, 2001).

\section{Statistical analysis}

All data are expressed as means and standard deviation. Statistical analysis was performed with oneway analysis of variance (ANOVA), followed by Tukey's Multiple Comparison Test using GraphPad Prism Software and $P<0.05$ was considered as significant. $* * \mathrm{P}<0.05$; $* * * \mathrm{P}<0.01$ when compared with control group and ${ }^{\# \#} \mathrm{P}$ $<0.05 ;{ }^{\# \#} \mathrm{P}<0.01$ when compared with diabetic group.

\section{RESULTS}

\section{Effect of the baicalein treatment on blood glucose level, body weight, HbA1c and TBARS level}

Measurement of blood glucose levels and body weight are important factors in the diabetic study (Pournaghi et al., 2012). Diabetic rats showed a significant $(P<0.05)$ increase in blood glucose levels and significant $(P<0.05)$ decrease in body weight when compared to normal control rats. Administration of baicalein ( $40 \mathrm{mg} / \mathrm{kg}$ b.wt.day) in diabetic rats significantly $(P<0.05)$ lowered the blood glucose level (Figure 1A) and increased body weight (Figure 1B) when compared to untreated diabetic rats. Similarly, HbA1c level in diabetic rats receiving baicalein treatment was significantly $(P<0.05)$ lower than for untreated diabetic rats (Figure 1C). The level of TBARS has been demonstrated to be a reliable marker for oxidative stress (Al-Dosari et al., 2017). There was a significant $(P<0.05)$ increase in TBARS in the liver of diabetic rats compared to normal control rats. Baicalein
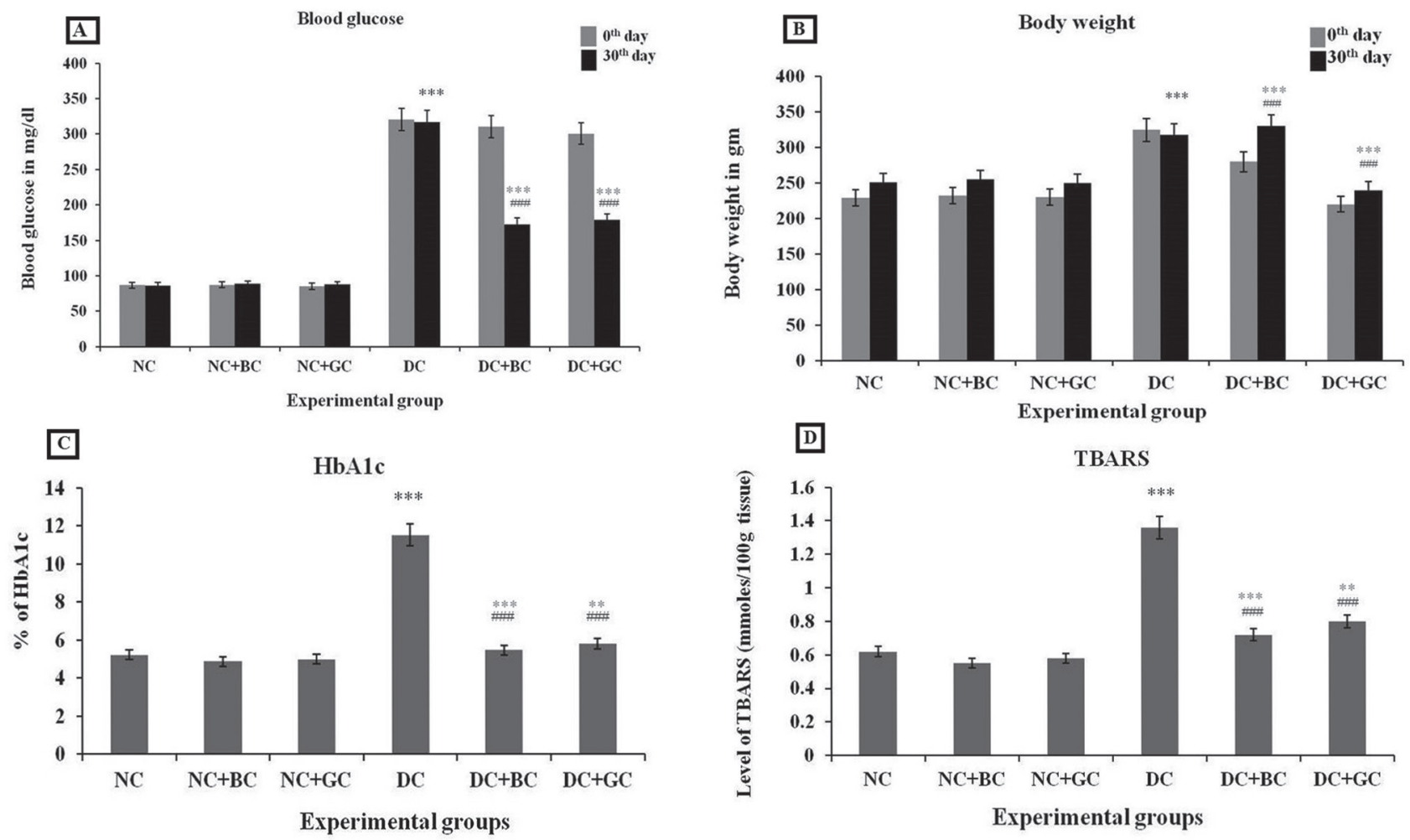

FIGURE 1 (A-D) - Effect of baicalein supplementation on blood glucose, body weight, \% HbA1C and TBARS levels of rats in different experimental groups. Data were expressed as mean \pm SD and analyzed using one-way ANOVA followed by Tukey's Multiple Comparison Tests. Values are statistically significant at $P<0.05 ; * * \mathrm{P}<0.05 ; * * * \mathrm{P}<0.01$ when compared with control group and ${ }^{\#} \mathrm{P}<0.05 ;{ }^{\# \#} \mathrm{P}<0.01$ when compared with diabetic group. $\mathrm{NC}$ : normal control, $\mathrm{NC}+\mathrm{BC}$ : normal control treated with baicalein, $\mathrm{NC}+\mathrm{GC}$ : normal control treated with glibenclamide, $\mathrm{DC}$ : diabetic control, $\mathrm{DC}+\mathrm{BC}$ : diabetic rats treated with baicalein, $\mathrm{DC}+\mathrm{GC}$ : diabetic rats treated with glibenclamide. 
treatment significantly $(P<0.05)$ inhibited the formation of TBARS in liver tissue and reduced TBARS level in the treatment group when compared to diabetic control rats (Figure 1D). Statistical differences $(P<0.05)$ were also found in $(\mathrm{DC}+\mathrm{BC})$ and $(\mathrm{DC}+\mathrm{GC})$ rats as compared to normal control rats in all the above studied parameters.

\section{Effect of the treatment on biochemical parameters}

The aspartate transaminase (AST) and alanine transaminase (ALT) activities were measured for the detection of possible liver damage. Activities of serum AST, ALT in the control and experimental groups are illustrated in Figure 2A and Figure 2B. There was a significant $(P<0.05)$ increase in the activities of AST, ALT in the serum of diabetic rats when compared to normal control rats. Treatment with baicalein to diabetic rats significantly $(P<0.05)$ decreased the enzymatic activities of AST and ALT. Significant $(P<0.05)$ reduction in triglyceride levels was observed in the treatment group compared to the diabetic control group (Figure 2C), which
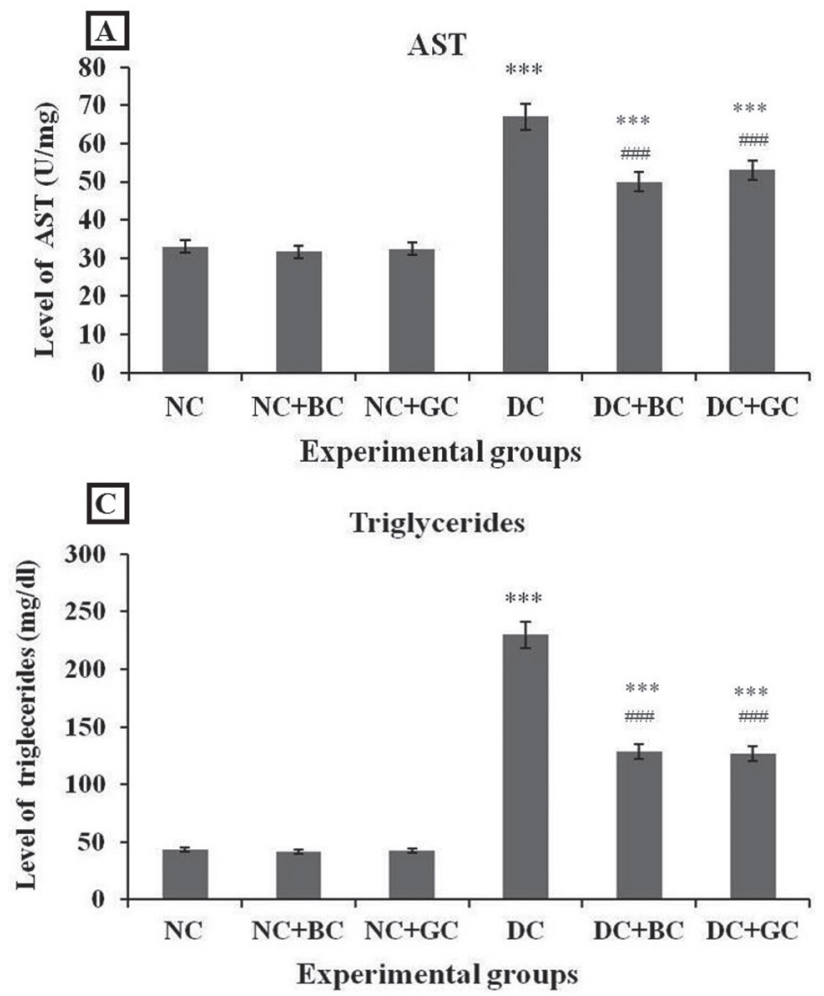

indicates that baicalein possesses a hypotriglyceridemic effect. A similar trend was observed in total cholesterol levels (Figure 2D). Reduction of circulating triglyceride and total cholesterol is an important aspect of the treatment of diabetes (Bitzur et al., 2009).

\section{Effect of the treatment on activities of antioxidant enzymes and gene expression}

The activities of enzymatic antioxidants such as superoxide dismutase (SOD), catalase (CAT), glutathione (GSH) and glutathione peroxidase (GPx) in the liver tissues of control and treatment group of rats are depicted in Figure 3(A-D). A significant $(P<0.05)$ reduction in the activities of SOD, CAT, GSH and GPx in the liver of STZNA administered rats was observed. However, treatment with baicalein and glibenclamide increased the level of enzymatic antioxidant in the liver of diabetic rats, this increase was more significant $(P<0.01)$ in baicalein than glibenclamide $(P<0.05)$ treatment groups. qPCR results showed that gene expression levels of main antioxidant enzymes $S O D, C A T, G S H$, and $G P x$ were suppressed
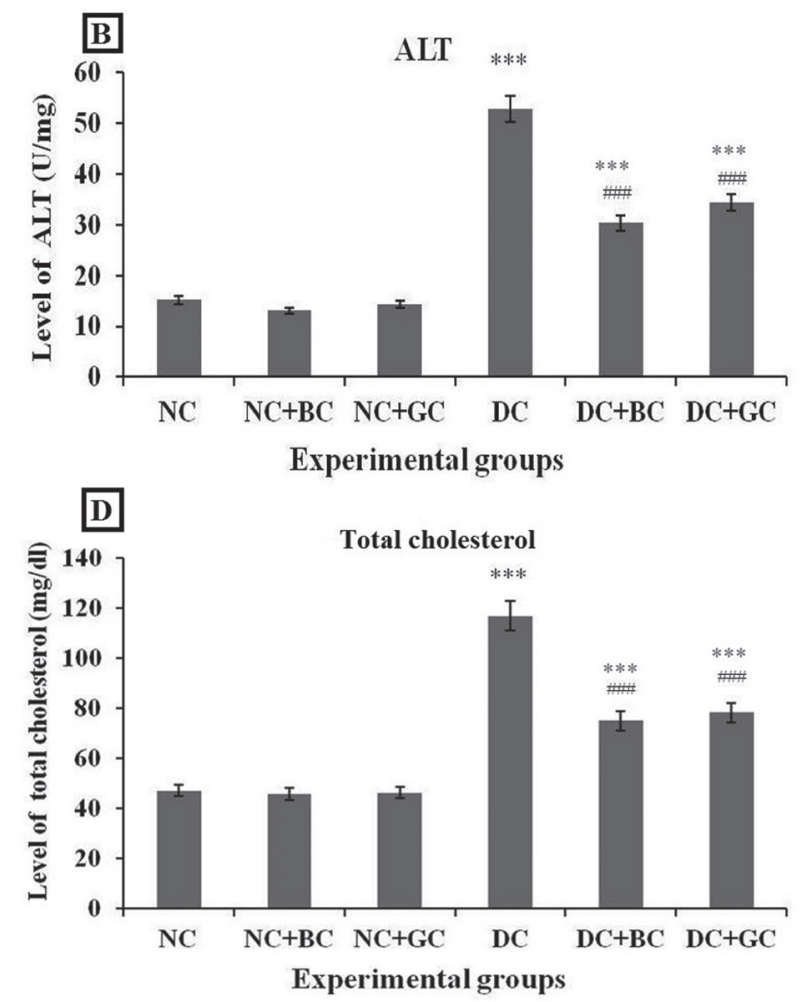

FIGURE 2 (A-D) - Effect of baicalein supplementation on AST, ALT, Triglycerides and Total cholesterol in different experimental groups. Data were expressed as mean \pm SD and analyzed using one-way ANOVA followed by Tukey's Multiple Comparisons Tests. Values are statistically significant at $P<0.05 ; * * \mathrm{P}<0.05 ; * * * \mathrm{P}<0.01$ when compared with control group and ${ }^{\#} \mathrm{P}<0.05$; ${ }^{\#} \mathrm{P}<0.01$ when compared with diabetic group. $\mathrm{NC}$ : normal control, $\mathrm{NC}+\mathrm{BC}$ : normal control treated with baicalein, $\mathrm{NC}+\mathrm{GC}$ : normal control treated with glibenclamide, $\mathrm{DC}$ : diabetic control, $\mathrm{DC}+\mathrm{BC}$ : diabetic rats treated with baicalein, $\mathrm{DC}+\mathrm{GC}$ : diabetic rats treated with glibenclamide. 

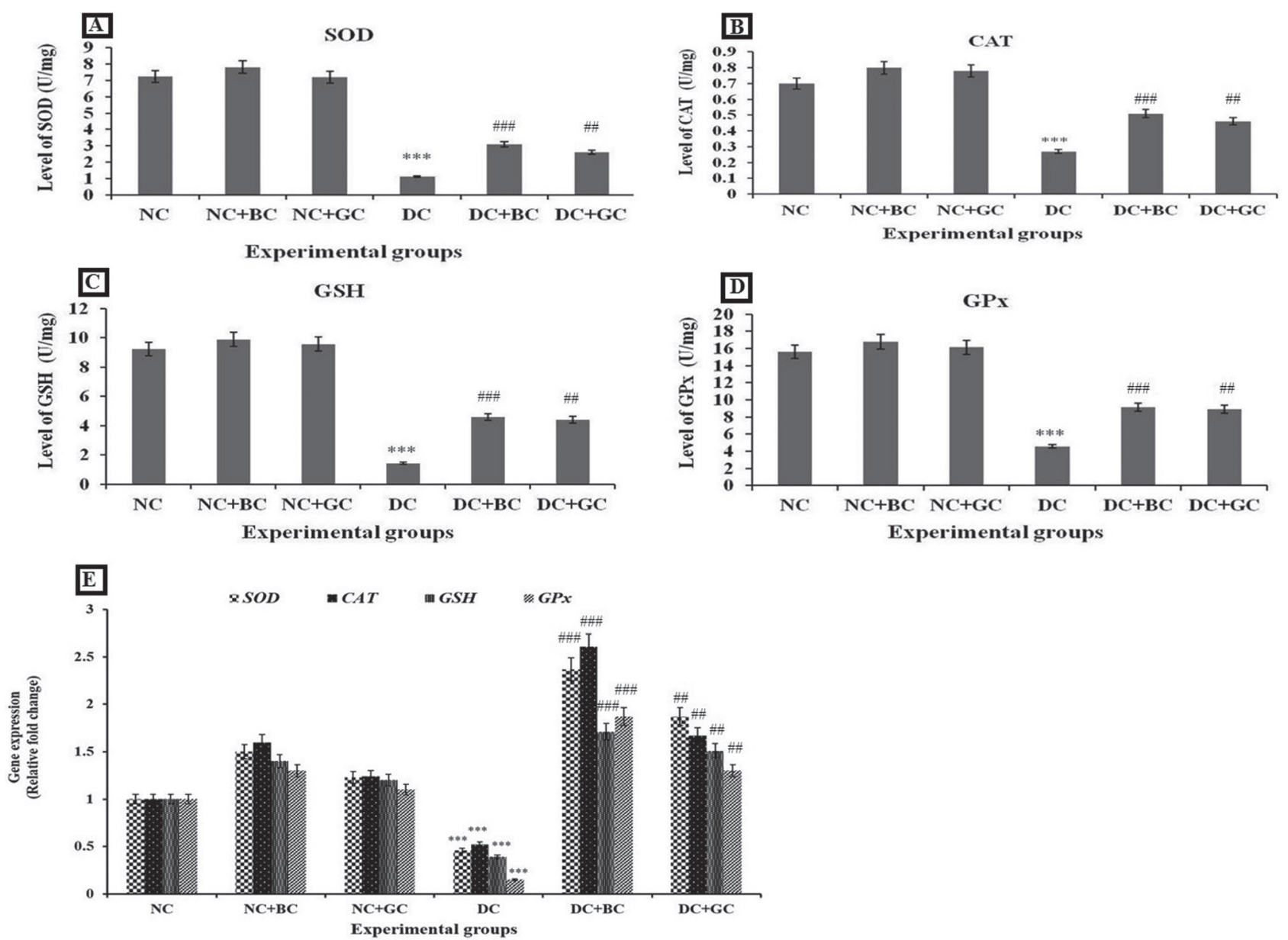

FIGURE 3 (A-E) - Effect of baicalein supplementation on activities of antioxidant enzymes and gene expression in different experimental groups. Data were expressed as mean \pm SD and analyzed using one-way ANOVA followed by Tukey's Multiple Comparisons Tests. Values are statistically significant at $P<0.05 ; * * \mathrm{P}<0.05 ; * * * \mathrm{P}<0.01$ when compared with control group and ${ }^{\#} \mathrm{P}<0.05 ;{ }^{\# \#} \mathrm{P}<0.01$ when compared with diabetic group. $\mathrm{NC}$ : normal control, $\mathrm{NC}+\mathrm{BC}$ : normal control treated with baicalein, $\mathrm{NC}+\mathrm{GC}$ : normal control treated with glibenclamide, $\mathrm{DC}$ : diabetic control, $\mathrm{DC}+\mathrm{BC}$ : diabetic rats treated with baicalein, $\mathrm{DC}+\mathrm{GC}$ : diabetic rats treated with glibenclamide.

in diabetic rats (Figure 3E). Treatment with baicalein significantly $(P<0.05)$ increased the expression of antioxidant genes in diabetic rat liver tissues. Expression levels were seen to be greater in baicalein treated rats than glibenclamide treated rats.

\section{DISCUSSIONS}

Diabetes mellitus is a severe health problem worldwide. An aging population, increased urbanization and more sedentary lifestyles have been linked to increase in the prevalence of diabetes (King, Aubert, Herman, 1998). The absence of a perfect cure for diabetes as well as the potential side effects of most of the antidiabetic medications has led many researchers to identify natural substances that show potent hypoglycemic activity with fewer side effects (Saxena, Vikram, 2004). As oxidative stress plays the central role in the pathogenesis and progression of diabetic complications, therefore, it is believed that antioxidant compounds would prevent and/or delay the progression of diabetic complications (Brownlee, 2001). The present study was conducted to assess the effects of baicalein on diabetes-induced oxidative stress by evaluating antioxidant enzyme activities and expression of antioxidant genes in the STZ-NA induced diabetic rats. Administration of STZ partially damages pancreatic cells (Szkudelski, 2012). The induction of diabetes with STZ in rat models caused a significant increase in blood glucose level, showing type II-like features as compared to the control group of rats, thus developing a state of oxidative stress. Baicalein, a flavonoid obtained from the roots of medicinal herb Scutellaria baicalensis Georgi, has been reported to have beneficial effects in diabetes-associated health complications (Ndisang, 2010). However, Fox et al. 
(2012) have demonstrated baicalein as an inducer of DNA damage and cell death by high-throughput genotoxicity assay in human ATAD5 cells. They showed that despite having genotoxic effects, baicalein did not cause any mutagenesis, further they observed that baicalein rapidly killed dividing cancer cells without causing potentially detrimental genomic instabilities and proved to be a chemotherapeutic agents. Recently, much interest has been focused on the antidiabetic effects of baicalein. In particular, it has been demonstrated that baicalein improves hyperglycemia and glucose intolerance, and promotes insulin secretion by inhibiting islet cell apoptosis in streptozotocin-induced diabetic mice (Fu et al., 2014). Baicalin, the glucuronide form of baicalein, also exerts beneficial effects on diabetes mellitus and its complications according to recent studies (Pu et al., 2012).

Lipid peroxide-mediated damage has been observed in the development of type 1 and type 2 diabetes. TBARS is the most commonly used indicator of lipid peroxidation (Lyons, 1991). In the present study, levels of TBARS were significantly elevated in liver, indicating increased oxidative stress and such results have also been represented by Jin et al. (2008) who reported elevated levels of TBARS in STZ-induced diabetic rats. Administration of baicalein significantly lowered the TBARS levels in diabetic treated groups compared with the untreated diabetic group, indicating inhibition of diabetes-induced oxidative stress. The present findings were in agreement with Sellamuthu et al. (2013) who reported reduced levels of TBARS upon oral administration of mangiferin and glibenclamide in diabetic rats in the liver and kidney tissues.

In general, increased blood glucose levels and severe loss of body weight characterize STZ-induced diabetes. The results of the present study are consistent with the observations of Gandhi, Sasikumar (2012). The spectrum of biochemical changes that typically occur in DM resembles those of liver diseases, from the secretion of abnormal liver enzymes to the end-stage liver failure (Moscatiello, Manini, Marchesini, 2007). The initial and most important indicators in assessing liver injury are levels of AST and ALT in in vivo (Hwang et al., 2005). Baicalein reduced the plasma triglycerides and total cholesterol contents which is an important aspect of the treatment of diabetes. AST and ALT levels are also showed improvement in the baicalein treated group as compared to diabetic control group. In diabetes, renal and hepatic failures are known to be the long-term consequences, therefore possible effects of the treatment with antioxidant on the hepatic tissue can be demonstrated by comparing the plasma levels of AST and ALT activities (Nathan, 2014). In our study, the AST and ALT levels of the baicalein treated group of rats were found to be within the normal range.

Diabetes-induced oxidative stress results in alteration of both enzymatic and non-enzymatic antioxidant systems. The liver is equipped with potent antioxidants systems such as SOD, CAT, and GSH enzyme family, including GST and GPx, not only to neutralize free radicals but also to protect the liver cells from oxidative damage (Parveen et al., 2010). Hence, we assessed the activity of the most important antioxidant enzymes such as SOD, CAT, GSH, and GPx in liver tissue of diabetic rats upon baicalein treatment. The relative changes in activity in diabetic tissues compared with control tissues indicate an altered antioxidant system. In this context, treatment with baicalein appears to have resulted in a considerable reversal of antioxidant enzymes that were altered in diabetic tissues. In the present study, treatment with baicalein increased the activity of antioxidant enzymes as compared to diabetic rats.

Previous research has proven that a decrease in SOD and CAT activities within a hyperglycaemic state leads to an increase in ROS, which eventually contributes to oxidation-induced liver damage (Han et al., 2006). The enzymatic activities of SOD, CAT, GSH, and GPx are significantly decreased in diabetes due to increased oxidative stress. In addition, to measure the activities of these enzymes, quantitative polymerase chain reaction (qPCR) was also used to study the expression levels of the antioxidant genes. In the present study, we found that the expression of these genes was decreased in the diabetic control group of rats as compared to the control group of rats. Induction of diabetes using STZ-NA was found to alter the expression of $S O D, C A T, G S H$, and GPX. The relative fold change of all the genes was observed to be significantly downregulated in diabetic control group and treatment with baicalein significantly upregulated the expression of all the tested genes. The present finding was in agreement with a recent study reporting that resveratrol administered to STZ-diabetic rats increased the gene expression of the antioxidant enzymes (Sadi, Baloglu, Pektas, 2015).

The importance of maintaining the redox balance and reducing the blood glucose levels plays important role in combating diabetic micro and macrovascular complications (Rask-Madsen, King, 2013). The present study showed that baicalein has the ability to ameliorate oxidative stress in liver of STZ-NA induced diabetic rats which were ascertained by improved glycemic and reduced lipid peroxidation along with improved antioxidant enzymatic activities. Moreover, it increased the expression pattern of the antioxidant genes in liver of 
STZ-NA induced diabetic rats. Antioxidant therapy is a potential future therapeutic strategy; increasing antioxidant levels in patients with DM-induced oxidative damage that may hopefully counter the effects of oxidative stress and inflammation, thereby reducing the severity of diabetic complications. The intervention for oxidative stress reduction is necessary for the overall therapy of diabetes which highlights the importance of antioxidants such as baicalein in the treatment of diabetes. Furthermore, the present study may contribute for future studies to establish pharmacological targets for novel therapies to prevent, reverse, or delay the onset of diabetic complications.

\section{ACKNOWLEDGEMENTS}

The authors are grateful to Department of Biotechnology for the research grant (BT/362/NE/ $\mathrm{TBP} / 2012$ ) extended towards completion of this project.

\section{CONFLICT OF INTEREST}

Authors declared that there is no conflict of interests.

\section{REFERENCES}

Aboonabi A, Rahmat A, Othman F. Antioxidant effect of pomegranate against streptozotocin-nicotinamide generated oxidative stress induced diabetic rats. Toxicol Rep. 2014;1:91522.

Al-Dosari DI, Ahmed MM, Al-Rejaie SS, Alhomida AS, Ola MS. Flavonoid naringenin attenuates oxidative stress, apoptosis and improves neurotrophic effects in the diabetic rat Retina. Nutrients. 2017;9(10):E1161.

Ayepola OR, Brooks NL, Oguntibeju OO. Oxidative stress and diabetic complications: the role of antioxidant vitamins and flavonoids. In Oguntibeju O, editor. Antioxidant-antidiabetic agents and human health. London: In Tech; 2014.

Bitzur R, Cohen H, Kamari Y, Shaish A, Harats D. Triglycerides and HDL cholesterol: stars or second leads in diabetes?. Diabetes Care. 2009;32(suppl 2):S373-S7.

Brownlee M. Biochemistry and molecular cell biology of diabetic complications. Nature. 2001;414(6865):813-20.

Chi YS, Lim H, Park H, Kim HP. Effects of wogonin, a plant flavone from Scutellaria radix, on skin inflammation: in vivo regulation of inflammation-associated gene expression. Biochem Pharmacol. 2003;66(7):1271-8.
Dehghan P, Gargari BP, Asgharijafarabadi M. Effects of high performance inulin supplementation on glycemic status and lipid profile in women with type 2 diabetes: a randomized, placebo-controlled clinical trial. Health Promot Perspect. 2013;3(1):55-63.

Elmali E, Altan N, Bukan N. Effect of the sulphonylurea glibenclamide on liver and kidney antioxidant enzymes in streptozocin-induced diabetic rats. Drugs R D. 2004;5(4):203-8.

Fox JT, Sakamuru S, Huang R, Teneva N, Simmons SO, Xia M, et al. High-throughput genotoxicity assay identifies antioxidants as inducers of DNA damage response and cell death. PNAS. 2012;109(14):5423-8.

Fu Y, Luo J, Jia Z, Zhen W, Zhou K, Gilbert E, Liu D. Baicalein protects against type 2 diabetes via promoting islet $\beta$-cell function in obese diabetic mice. Int J Endocrinol. 2014; 2014:846742.

Gandhi GR, Sasikumar P. Antidiabetic effect of Merremia emarginata Burm. F. in streptozotocin induced diabetic rats. Asian Pac J Trop Biomed. 2012;2(4):281-6.

Gao Z, Huang K, Yang X, Xu H. Free radical scavenging and antioxidant activities of flavonoids extracted from the radix of Scutellaria baicalensis Georgi. Biochim Biophys Acta. 1999;1472(3):643-50.

Giacco F, Brownlee M. Oxidative stress and diabetic complications. Circ. Res. 2010;107(9):1058-70.

Gupta RK, Kesari AN, Murthy PS, Chandra R, Tandon V, Watal $\mathrm{G}$ et al. Hypoglycemic and antidiabetic effect of ethanolic extract of leaves of Annona squamosa L. in experimental animals. J Ethnopharmacol. 2005;99(1):75-81.

Gupta S, Mediratta PK, Singh S, Sharma KK, Shukla R. Antidiabetic, antihypercholesterolaemic and antioxidant effect of Ocimum sanctum (Linn) seed oil. Indian J Exp Biol. 2006;44(4):300-4.

Han D, Hanawa N, Saberi B, Kaplowitz N. Mechanisms of liver injury: III. Role of glutathione redox status in liver injury. Am J Physiol Gastrointest Liver Physiol. 2006;291(1):G1-G7.

Hwang HJ, Kim SW, Lim JM, Joo JH, Kim HO, Kim HM, et al. Hypoglycemic effect of crude exopolysaccharides produced by a medicinal mushroom Phellinus baumii in streptozotocininduced diabetic rats. Life Sci. 2005;76(26):3069-80. 
Jin L, Xue HY, Jin LJ, Li SY, Xu YP. Antioxidant and pancreasprotective effect of aucubin on rats with streptozotocin-induced diabetes. Eur J Pharmacol. 2008;582(1):162-167.

King H, Aubert RE, Herman WH. Global burden of diabetes, 1995-2025: prevalence, numerical estimates, and projections. Diabetes Care. 1998;21(9):1414-31.

Lenzen S. The mechanisms of alloxan and streptozotocininduced diabetes. Diabetologia. 2008;51(2):216-26.

Livak KJ, Schmittgen TD. Analysis of relative gene expression data using real-time quantitative PCR and the $2^{-\triangle \Delta C T}$ method. Methods. 2001; 25(4):402-8.

Li-Weber M. New therapeutic aspects of flavones: the anticancer properties of Scutellaria and its main active constituents Wogonin, Baicalein and Baicalin. Cancer Treat Rev. 2009;35(1):57-68.

Lyons TJ. Oxidized low-density lipoproteins, a role in the pathogenesis of atherosclerosis in diabetes? Diabet Med. 1991;8(5):411-19.

Maritim AC, Sanders RA, Watkins JB. Diabetes, oxidative stress, and antioxidants: a review. J Biochem Mol Toxic. 2003;17(1):24-37.

Masiello P, Broca C, Gross R, Roye M, Manteghetti M, Hillaire-Buys D, et al. Experimental NIDDM: development of a new model in adult rats administered streptozotocin and nicotinamide. Diabetes. 1998;47(2):224-9.

Misra HP, Fridovich I. The role of superoxide anion in the autoxidation of epinephrine and a simple assay for superoxide dismutase. J Biol Chem. 1972;247(10):3170-5.

Moscatiello S, Manini R, Marchesini G. Diabetes and liver disease: an ominous association. Nutr Metab Cardiovasc Dis. 2007;17(1):63-70.

Nathan DM. DCCT/Edic Research Group. The diabetes control and complications trial/epidemiology of diabetes interventions and complications study at 30 years: overview. Diabetes Care. 2014;37(1):9-16.

Ndisang JF. Role of heme oxygenase in inflammation, insulin-signalling, diabetes and obesity. Mediators Inflamm. 2010;2010(art.359732):1-18.
Nizamutdinova IT, Jin YC, Chung JI, Shin SC, Lee SJ, Kim HJ. The anti-diabetic effect of anthocyanins in streptozotocininduced diabetic rats through glucose transporter 4 regulation and prevention of insulin resistance and pancreatic apoptosis. Mol Nutr Food Res. 2009;53(11):1419-29.

Ohkawa H, Ohishi N, Yagi K. Assay for lipid peroxidation in animal tissues by thiobarbituric acid reaction. Anal Biochem. 1979;95(2):351-8.

Parveen K, Khan MR, Mujeeb M, Siddigui WA. Protective effects of Pycnogenol on hyperglycemia-induced oxidative damage in the liver of type 2 diabetic rats. Chem Biol Interact. 2010;186(2):219-27.

Patel DK, Kumar R, Laloo D, Hemalatha S. Diabetes mellitus: an overview on its pharmacological aspects and reported medicinal plants having antidiabetic activity. Asian Pac J Trop Biomed. 2012;2(5):411-20.

Phillips M, Cataneo RN, Cheema T, Greenberg J. Increased breath biomarkers of oxidative stress in diabetes mellitus. Clin Chim Acta. 2004;344(1):189-94.

Pournaghi P, Sadrkhanlou RA, Hasanzadeh S, Foroughi A. An investigation on body weights, blood glucose levels and pituitary-gonadal axis hormones in diabetic and metformintreated diabetic female rats. Vet Res Forum. 2012;3(2):79-84.

Pu P, Wang XA, Salim M, Zhu LH, Wang L, Chen KJ, et al. Baicalein, a natural product, selectively activating AMPK $\alpha$ (2) and ameliorates metabolic disorder in diet-induced mice. Mol Cell Endocrinol. 2012;362(1):128-38.

Rask-Madsen C, King GL. Vascular complications of diabetes: mechanisms of injury and protective factors. Cell Metab. 2013;17(1):20-33.

Raza H, Prabu SK, John A, Avadhani NG. Impaired mitochondrial respiratory functions and oxidative stress in streptozotocininduced diabetic rats. Int J Mol Sci. 2011;12(5):3133-47.

Rotruck JT, Pope AL, Ganther HE, Swanson AB, Hafeman DG, Hoekstra W. Selenium: biochemical role as a component of glutathione peroxidase. Science. 1973;179(4073):588-90.

Sadi G, Baloglu MC, Pektaş MB. Differential gene expression in liver tissues of Streptozotocin-induced diabetic rats in response to resveratrol treatment. PloSOne. 2015;10(4 e0124968):1-21. 
Saxena A, Vikram NK. Role of selected Indian plants in management of type 2 diabetes: a review. J Altern Complement Med 2004;10(2):369-78.

Sedlak J, Lindsay RH. Estimation of total, protein-bound, and nonprotein sulfhydryl groups in tissue with Ellman's reagent. Anal Biochem. 1968;25(1):192-205.

Sellamuthu PS, Arulselvan P, Kamalraj S, Fakurazi S, Kandasamy M. Protective nature of mangiferin on oxidative stress and antioxidant status in tissues of streptozotocin-induced diabetic rats. ISRN Pharmacol. 2013;12(2013):1-10.

Szkudelski T. Streptozotocin-nicotinamide-induced diabetes in therat: characteristics of the experimental model. Exp Biol Med. 2012;237(5):481-90.
Takahara S, Hamilton HB, Nell JV, Kobra TY, Ogura Y, Nishimura ET. Hypocatalasemia: a new genetic carrier state. J Clin Investig. 1960;39(4):610-9.

Wang CZ, Mehendale SR, Yuan CS. Commonly used antioxidant botanicals: active constituents and their potential role in cardiovascular illness. Am J Chin Med. 2007;35(4):543-58.

Yajnik CS. The insulin resistance epidemic in India: fetal origins, later lifestyle, or both? Nut Rev. 2001;59(1 pt.1):1-9.

Received for publication on $17^{\text {th }}$ March 2018 Accepted for publication on $14^{\text {th }}$ May 2018 